\title{
Experimental Study of Pool Effect of Shear, Flexure and Torsion on SFRC Beams
}

\author{
Mohammad Israil, M S Jafiri, Pushpendra Kumar Sharma, Anshul Garg
}

\begin{abstract}
Flexural, torsional, compressive and shear behavior of Steel Fiber Reinforced Concrete (SFRC) is already studied individually but none has studied the performance of SFRC beams under a combined effect of more than one state i.e. tension, flexure, torsion, compression and shear in general by now. In this study M20 grade of concrete beams under composite behavior of flexure, shear and torsion with different compositions of fibers mix were investigated. The dimensions of specimen beams was $100 \mathrm{~mm} \times 100 \mathrm{~mm} \times 500 \mathrm{~mm}$ and straight cylindrical fibers of length $0.28 \mathrm{~mm}$ and aspect ratio 100 were mixed. A total of 48 specimen were casted and tested such that for every percentage of fiber and each torsion value three beams were tested. Hence there are four torsion values $0,61.75,119.41$ and $176.53 \mathrm{~N}-\mathrm{m}$ are applied $(4 \times 3 \times 4=48)$ It was found during study that ultimate bending stress and deflection increases due to increase in torsion where as the ductility reduced with the torsion enhancement for a specific fraction of fiber content.
\end{abstract}

Keywords: About four key words or phrases in alphabetical order, separated by commas.

\section{INTRODUCTION}

Given its long history, it is surprising that the introduction of fibers to improve the material properties had not advanced a great deal in the period up to the early 1930's. However, post 1930 progress has been more impressive with the most significant gains made after 1960 . This can be attributed to both the appearance of man-made fibers and the evolution of a more meticulous scientific approach to the computation of cement based composite behavior. Due to low tensile strength; ordinary concrete cracks when undergoes tensile stresses and impact loads and to solve this cracking problem, reinforcement bars of steel are located inside the ordinary concrete. The reinforcement can also be provided in fibers form which can be uniformly cast in and distributed all over the concrete medium. These fibers create a connection within

Revised Manuscript Received on July 28, 2020.

* Correspondence Author

Mohammad Israil, Associate Professor, University Polytechnic, Aligarh Muslim University, Aligarh, U.P., India. E-mail: misrailamu@yahoo.com

M.S. Jafiri, Associate Professor, Department of Civil Engineering, Aligarh Muslim University, Aligarh, U.P., India. E-mail: jafirims@live.com

Pushpendra Kumar Sharma*, Professor, Department of SCE, Lovely Professional University, Phagwara, Punjab, India. E-mail: p.sharmaji10@gmail.com

Anshul Garg, Assistant Professor, Department of SCE, Lovely Professional University, Phagwara, Punjab, India. E-mail: anshulgarg2008@gmail.com

(C) The Authors. Published by Blue Eyes Intelligence Engineering and Sciences Publication (BEIESP). This is an open access article under the CC BY-NC-ND license (http://creativecommons.org/licenses/by-nc-nd/4.0/) the cracks and offer enhanced performance of the concrete structure. The betterment extent rests on the factors like strength, aspect ratio, modulus, superficial attachment features, fiber type, amount and direction etc. When Steel fibers are casted in concrete then it enhances load carrying capacity by shifting the burden from the concrete to the fibers. Shear distortion at the fiber-matrix interface consequences in conflicting physical stuffs between the concrete and the fibers. Steel fibers show added role to prevent cracking and increase confrontation to dynamic or impact loading or to attack substantial collapse. Especially, synthetic fibers can be useful to non-structural and non-primary load bearing practices.

\section{LITERATURE REVIEW}

Normal concrete is very weak against tensile stresses in combination with inelastic performance resulting in abrupt tensile letdown lacking any notice in advance. For constructions that can result to main structural failure and so concrete needs certain arrangement of tensile strengthening to counter its fragility, to increase its tensile bearing strength and strain capability so that these can be used in structural practices. For a long steel is being applied as a choicest material for concrete tensile strengthening, historically. Steel reinforcement is purposefully located in the body of concrete where there is an expected tensile stress to occur so as to make the steel reinforcement very effective and efficient. Various researches have been performed and in a research by Romualdi and Batson [1] impact test on fiber reinforced concrete specimens was conducted where it was found that adding narrow gapped continual steel fibers in concrete improved the cracking strength. Micro cracks were also prevented by the application of pinching forces at the tips of cracks which delayed the further propagation of cracks just because of these steel fibers. Further in 1979 Narayanan and Toorani [2] provides information concerning the behaviour of plain and fiber reinforced concrete for range of normal and high strength levels under direct shear. The principal parameters investigated were like volume percentage of steel fibers, compressive strong point of concrete, aspect of steel fibers. Formulations were correspondingly proposed for cracks and ultimate shear prediction for SFRC for initially uncracked push-off specimens with various fiber volume and aspect ratio. The cracking behavior of steel fiber reinforced concrete is founded to be reduced with smaller crack spacing and reduction in crack width as compared to plain steel reinforced beams Bichoff [3].

Published By:

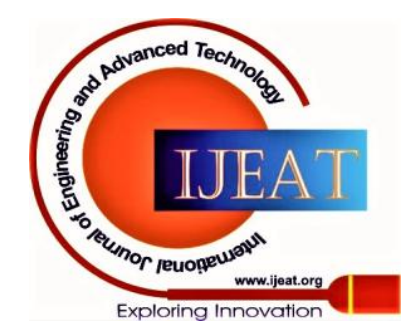




\section{Experimental Study of Pool Effect of Shear, Flexure and Torsion on SFRC Beams}

Further experimental studies on impact confrontation of steel fiber protected concrete is done by drop weight test method where hook ended fibers of $35 \mathrm{~mm}$ length and $0.55 \mathrm{~mm}$ in diameter and founded that there is an improvement in first crack, failure strength and residual impact Song et al [4].

\section{EXPERIMENTAL PROGRAM}

An exclusive experimental set up was made to establish the effect of SFRC with changing fused mixes and fractions of fibers. Specimen beams sized with $100 \times 100 \times 500$ cubic mm of Mix M20 grade of concrete were casted with varying fractions i.e. $0 \%, 0.5 \%, 0.75 \%$ and $1 \%$ of fibers by weight.

\section{A. Properties of Concrete Constituents}

The various constituents of concrete were tested for physical properties without any harmful elements so as not to affect the complex behavior.

OPC 43 grade was used conforming to IS 4031: (1999) for (mm) (Le-Chatelier's Test), specific gravity, Compressive strength after 7 and 28 days of cement. The results were 29.5\%, 34 and <600 minutes, $2 \mathrm{~mm}, 3.15,21$ and $40 \mathrm{MPa}$ respectively which are very near to $30 \%, 30$ minutes (min) and 600 minutes (max), $10 \mathrm{~mm}$ (max), 3.15, 33 and $43 \mathrm{MPa}$; the suggested standards

Locally available coarse sand as fine aggregates used was graded using IS sieves and were of grading zone II. The fineness modulus and specific gravity were determined as 2.83 and 2.45. IS 383: (1970) was followed for the tests to be performed.

Locally available coarse aggregate of crushed stone $10 \mathrm{~mm}$ and $20 \mathrm{~mm}$ graded used in concrete mix as the mainly quartzite in mineralogical composition. The fineness modulus and specific gravity of $10 \mathrm{~mm}$ and $20 \mathrm{~mm}$ aggregate as determined as per IS code was 2.60, 5.92 and 2.64 and 6.98 respectively.

Potable water was used in all operations to take care quality of water.

Steel wire pieces of $2.8 \mathrm{~cm}$ length, diameter $0.28 \mathrm{~mm}$ and aspect ratio 100 were mixed with concrete in the weight proportions $0 \%, 0.5 \%, 0.75 \%$ and $1.0 \%$.

\section{B. Mix Design of M20 Grade Concrete}

The ordinary M20 mix of concrete was considered as per the guidelines of IS-10262: (1982), steel threads were mixed by weight with percentage fractions of $0.0 \%, 0.5 \%, 0.75 \%$ and $1.0 \%$ to the ordinary mixes to obtain normal strength fibre reinforced concrete. The constituents of the concrete mixes are listed in Table 1.

Table 1. Constituents of Materials to be Used for M20 Grade Concrete

\begin{tabular}{|c|c|c|c|c|}
\hline $\begin{array}{c}\text { Material } \\
\text { Type }\end{array}$ & Cement & $\begin{array}{c}\text { Fine } \\
\text { Aggregate }\end{array}$ & $\begin{array}{c}\text { Coarse } \\
\text { Aggregate }\end{array}$ & $\begin{array}{c}\text { Water/ } \\
\text { Cement } \\
\text { Ratio }\end{array}$ \\
\hline $\begin{array}{c}\text { Amount in } \\
\mathbf{1} \text { cubic } \\
\text { meter of } \\
\text { concrete }\end{array}$ & 372 & 579.6 & 1159.85 & 0.5 \\
\hline
\end{tabular}

The mix design was done as per IS-10262: (1982) and specimens were casted which were taken out of molds after 24 normal consistency, initial and final setting times, soundness

hours of casting, labelled specimens were submerged in water for curing a period of 28 days. The completely cured concrete beam samples were taken out four weeks later and after surface dried brought to be tested at room temperatures under two point load procedure and load vs central deflections readings were observed.

\section{Tests on Samples}

The combined effect of flexure, torsion and shear was studied experimentally in the laboratory. Different type of experimental setup is required in which SFRC beams were tested in for flexure under two point loads. The central deflection was determined using dial gauges supported by a plate on both the sides. Pure bending was achieved by applying point loads exactly at $1 / 3$ rd point of length from both sides with center of beam. The torsion was applied in such a way that a long iron girder was attached with one end of the beam and the other was clamped not to rotate. The arrangement of torque application is as shown in Figure $1 \& 2$ The torsion was applied as $0.0 \mathrm{~N}-\mathrm{m}, 61.75 \mathrm{~N}-\mathrm{m}, 119.41 \mathrm{~N}-\mathrm{m}$ and $176.53 \mathrm{~N}-\mathrm{m}$ by varying the load on the iron girder.

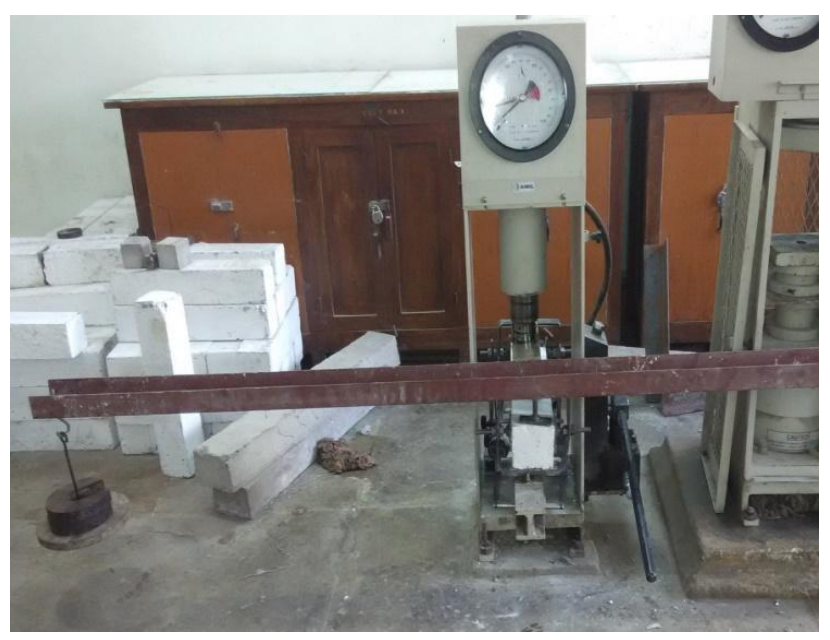

Figure 1. Set Up for Flexure, Torsion and Shear

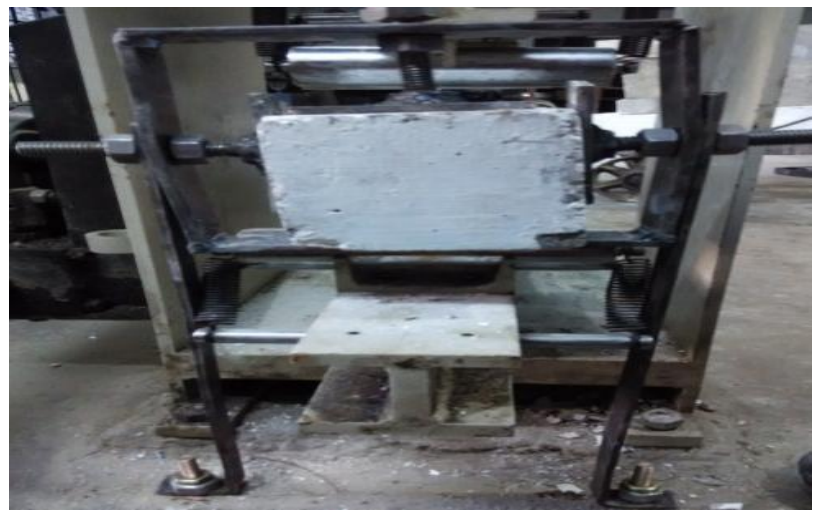

Figure 2. Set up of Clamp to Hold Far End

\section{OUTCOMES AND DEBATE}

Use either SI (MKS) or CGS as primary units. (SI units are encouraged.) English units may be used as secondary units (in parentheses). An exception would be the use of English units as identifiers in trade, such as "3.5-inch disk drive". Avoid combining SI and CGS units, such as current in amperes and magnetic field in oersteds.

Published By:

Blue Eyes Intelligence Engineering

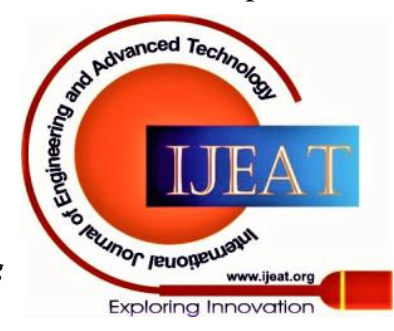


This often leads to confusion because equations do not balance dimensionally. If you must use mixed units, clearly state the units for each quantity that you use in an equation. Do not mix complete spellings and abbreviations of units: "Wb/m2" or "webers per square meter", not "webers/m2". Spell out units when they appear in text: ". . . a few henries", not ". . . a few H".

\section{A. SFRC under Compression}

M20 grade SFRC cubes of size 150mmx150mmx150mm were tested in uniaxial compression with varying percentage of fibres from $0.0 \%$ to $1.0 \%(0.0,0.5,0.75$, and $1.0 \%)$ by weight. The stress - strain diagram was then found.

\section{B. SFRC under Splitting Tensile Strength}

M20 grade SFRC cylinders of size 150mm dia and $300 \mathrm{~mm}$ height were tested for splitting tensile strength with varying percentage of fibres from $0.0 \%$ to $1.0 \%(0.0,0.5,0.75$, and $1.0 \%$ ) by weight. The stress - strain diagram was then found.

\section{SFRC under Flexure, Torsion and Shear}

Similar to the cases $(0.0 \%, 0.5 \%$ and $0.75 \%)$ the specimen beams with $1 \%$ fiber amount by volume were exposed to a confining torsion $0,61.75,119.41,176.53 \mathrm{~N}-\mathrm{m}$. At torsion load was $0 \mathrm{Nm}$, the specimen beams failed at $15 \mathrm{kN}$ ultimate load with $0.68 \mathrm{~mm}$ of ultimate deflection. The load bearing ability reduced to $14 \mathrm{kN}$ with decreased deflection of 0.605 $\mathrm{mm}$ on raising the torsion up to $61.75 \mathrm{~N}-\mathrm{m}$. The beams subjected to torsion of $119.41 \mathrm{~N}$-m were observed to bear an ultimate load $12 \mathrm{kN}$ and miscarried at a central deflection $0.515 \mathrm{~mm}$. On exposing the specimen beams to a torsion value $176.53 \mathrm{~N}-\mathrm{m}$, the ultimate load bearing capability of the specimen decreased to $11 \mathrm{kN}$. The deflection observed in sample beams was $0.435 \mathrm{~mm}$. Figure 3 shows the load deflection curve at $1.0 \%$ fibers.

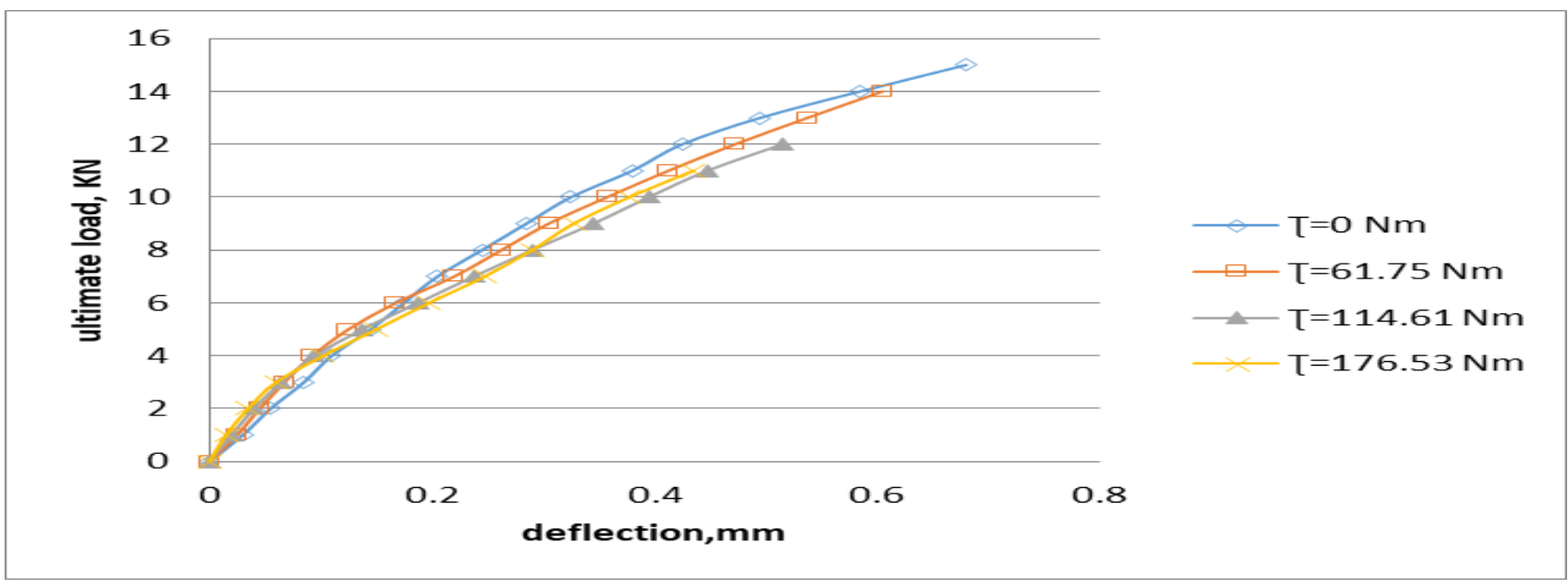

Figure 3. Ultimate load vs. deflection plots for $1.0 \%$ Fiber with varying torsion

\section{CONCLUSIONS}

1. In the specimen beam tested under joint effect of flexure, torsion and shear the ultimate bending stress and ultimate central deflection decreases with the increase of torsion for a specific fiber content.

2. The central deflection value at ultimate load rises with the upsurge of fiber percentage for a specific torsion in the specimen beams.

3. At the torsion value of $119.41 \mathrm{Nm}$; the bending stress surges from $3.6 \mathrm{~N} / \mathrm{mm}^{2}$ to $4.8 \mathrm{~N} / \mathrm{mm}^{2}$ by an extreme value of $27.27 \%$ with the increment of fiber content right from $0.0 \%$ to $1.00 \%$ by weight.

\section{REFERENCES}

1. J.P., Romualdi, and G.B., Baston. "Mechanics of crack arrest in concrete with closely spaced reinforcement" Journal of the Engineering Mechanics Division., EM3. Proceedings of the American Society of Civil Engineers, Vol. 89, (1963), pp. 147-168.

2. R. Narayanan and G.Z. Toorani, "Fiber reinforced concrete in pure torsion and in combined bending and torsion". Proceedings Institution of Civil engineers, London Part 2, Vol. 67, December (1979). pp 987-1001.

3. P. Bichoff "Tension, Stiffening and Cracking of Steel Fibre Reinforced Concrete", Journal of Materials in Civil Engineering, ASCE, March/April (2003).

4. Song, Hwang, Shou. "Statistical Evaluation for Impact Resistance of Steel Fibre reinforced Concrete", Magazine of Concrete Research, Vol. 56, No. 8, (2004) pp. 437-442.

5. J. Thomas, and A. Ramaswamy, "Mechanical Properties of Steel Fiber-Reinforced Concrete", Journal of Materials in Civil Engineering, Vol. 19, No. 5, 385-389, May 1, 2007

\section{AUTHOR'S PROFILE}

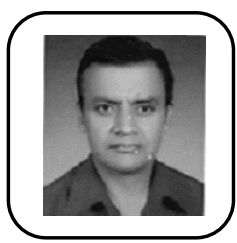

Dr. Pushpendra Kumar Sharma, born in December 1963, Graduated (1991), Post Graduated (1996) from Aligarh Muslim University, Aligarh, India in field of Civil Engineering in 1996 and with the same Research Centre completed PhD in Civil Engineering with Specialization in Environmental and Water Resources Engineering in 2016, is a Professor in School of Civil Engineering, Lovely Professional University, Phagwara, Punjab, India. He is having a total experience of more than 30 years; 9.5 years construction industry and 20.5 years of teaching. He is having his areas of interests like Environmental and Water Resources, Green Buildings, Capacity buildings, earthquake resistant buildings, energy efficient buildings, water and wastewater treatment technologies, environmental designs, sustainable construction project management, river pollution control and industrial wastewater treatment etc. In addition to teaching he has served and officiated many administrative designation like Dean Academics, Dean Students Welfare, Warden, Chairman Construction Committee HCST etc. He has been the author of more than 80 International/Journals and Conference research papers.

Published By:

Blue Eyes Intelligence Engineering and Sciences Publication (C) Copyright: All rights reserved.

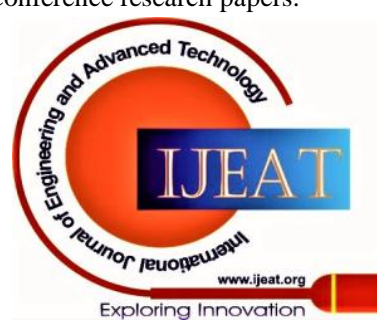


Experimental Study of Pool Effect of Shear, Flexure and Torsion on SFRC Beams

He is reviewer of Cogent Engineering International Journal of Tailor and Francis, Journal of Environmental Chemical Engineering and has reviewed many papers of the same. He has successfully organized National and International Conferences in the working institutions. He is life time member of Indain Molecular Society (IMS), Indian Science Congress Association (ISCA) and Institution of Engineers, India (IEI). Currently he is guiding 10 PhDs in Civil Engineering on various topics @ LPU.

He has guided one M.Tech and 4 more currently being guided in LPU. He has guided 155 B.Tech level projects on various topics of Civil Engineering. He has filed 8 patents out of which six published and rest in pipe line. He attended many workshops of international and national repute. He is successfully trained under National Programme for Capacity Building of Engineers in Earthquake Risk Management (NPCBEERM), organized by Department of Civil Engineering, Indian Institute of Technology, Madras.

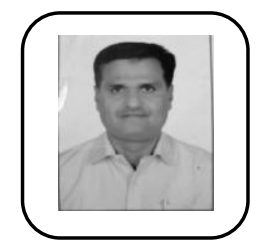

Mohammad Israil completed B. Sc. Engineering Civil in 1989 and M. Sc. Engineering (Building Engineering) in 1992 from Aligarh Muslim University, Aligarh. Currently pursuing Ph.D. in Structures. He has completed 25 years of service in AMU Aligarh. He is Associate Professor since 2007. $\mathrm{He}$ is also a Consultant Engineer for different government departments. His area of interest design and building material testing.

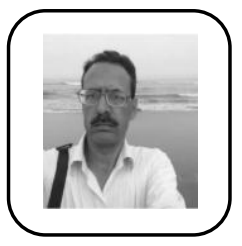

Dr. Muhammad Shamshuddin Jafiri completed B. Sc. Engineering Civil in 1989 and M. Sc. Engineering (Building Engineering) in 1992 from Aligarh Muslim University, Aligarh. He has completed his Ph.D. in Structures from IIT (DELHI) IN 1999. He has completed 25 years of service in AMU Aligarh. He is Associate Professor since 2007. He is also Consultant Engineer for different government departments. His area of interest is design and building material testing.

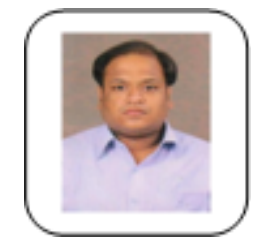

Anshul Garg born on March 14, 1983 completed his B.E. (Civil) in 2006 from Institute of Engineering and technology, Khandari, Agra affiliated to Dr. Bhimrao Ambedkar University, Agra and M.Tech. (Structural Engineering) in 2007 from Manipal University, Manipal, Karnataka is currently working as an Assistant Professor, in School of Civil Engineering, Lovely Professional University, Phagwara, Punjab, India. He is pursuing his $\mathrm{PhD}$ in Structural Engineering from SCE, LPU.

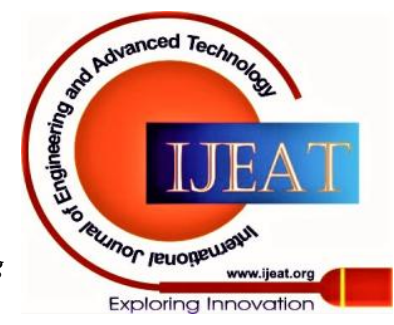

